\title{
Las implicancias psicopatológicas de la acedia en Evagrio Póntico
}

\author{
Santiago Hernán Vazquez*1
}

La presente comunicación intenta poner de relieve la contribución de Evagrio Póntico en la comprensión etiológica de ese padecimiento tan cercano a la melancolía moderna y a la depresión contemporánea, que él conceptualizó y sistematizó por primera vez: la acedia. Se ponen en relación con su aporte algunos elementos de la noción freudiana de melancolía y de la teoría de la autodiscrepancia acerca de la depresión, principalmente en lo que se refiere al rol del ideal del yo en el dinamismo etiopatogénico. En este contexto se evidencia la importancia histórica de la contribución evagriana que se anticipa a diversos planteamientos muy posteriores de la psicología y la psicopatología, e integra en una perspectiva espiritual la comprensión etiológica de la perturbación psíquica y su posible terapia.

Palabras claves: Acedia, depresión, Ideal del yo, Ideal de perfección

${ }^{* 1}$ Universidad Nacional de Cuyo - UNCuyo (Luján de Cuyo, Mendoza, AR). 


\section{Introducción}

El redescubrimiento de la obra de Evagrio Póntico llevado a cabo en las últimas décadas del siglo XX y en la actualidad, y los estudios científicos cada vez más abundantes acerca de su pensamiento, ${ }^{1}$ tienen en la profundización de la noción de acedia acaso su aporte más amplio y significativo. El Póntico es, en efecto, el primer sistematizador de un concepto que constituye hoy una referencia ineludible en la historia de la psicopatología y del pensamiento filosófico en general.

Si bien el término acedia se encuentra mencionado antes de Evagrio por Orígenes, por Simeón el nuevo teólogo, por Teodoro Studita y por San Atanasio (Guillaumont, 1971; Orígenes, 1962; Symeón, 1957; Studita, 1860), y posee además un origen filológico clásico, Evagrio es el primero en identificarlo, describirlo y explicarlo como padecimiento psicoespiritual. Digamos que Evagrio se apropia de un término presente en la literatura que lo antecede pero no suficientemente especificado, y le da una proyección y una extensión que no tenía hasta el momento. Bernard Forthomme llama la atención acerca del hecho de que Evagrio Póntico utilice para referirse a una experiencia aparentemente reconducible a la melancolía - concepto presente en el pensamiento clásico que nuestro pensador, amplio conocedor de la filosofía griega (Guillaumont, 2009), conocía en su letra fina - , el término griego $\alpha \kappa \eta \delta ı \alpha$, a la sazón poco usado y poco determinado (Forthomme, 2005). Rastreando los

${ }^{1}$ Entre los más recientes están, por ejemplo, los libros y artículos de Augustine Casiday (2013), de Diego Marchini (2009), de Giovanni Cataldo (2007), de Gabriel Bunge (2007, 2009), de Antoine Guillaumont (1996; 2009), de Bernard Forthomme (2000; 2005), de Paolo Bettiolo (2009), de Paul Géhin (2011), De Rubén Peretó Rivas (2011b; 2012), entre otros. Asimismo debe mencionarse el creciente número de ediciones de las obras de Evagrio Póntico, empezando por las ediciones críticas de la colección Sources Chrétiennes (1971, 1987b, 1993, 1998a, 2008a), y siguiendo por las italianas de Ciudad Nueva (1998b, 1999, 2010), de Qiqajon $(2005,2008)$ y de San Pablo (1996, 2006), o la castellana también de Ciudad Nueva (2013) o las inglesas de Cistercian Publications $(1970,2009)$ y de la Universidad de Oxford (1987a), por mencionar sólo algunas. 


\section{ARTIGO}

primeros usos de dicho término y su significación general (Forthomme, 2005; Peretó Rivas, 2013; Bouvier, 2005; Guillaumount, 1971), y confrontando éstos con la conceptualización que de él realiza Evagrio Póntico, se puede entrever la razón de su elección: aquella experiencia de atonía, de dispersión y de disgusto generalizado e inespecífico que aqueja a los monjes y, en general, a todo ser humano, es reconducible en sus causas a aquella actitud espiritual de descuido o huída de sí - surgida por lo que Forthomme llama "la experiencia solitaria de sí" y un deseo de sí frustrado (Forthomme, 2003) - que, en sentido general,

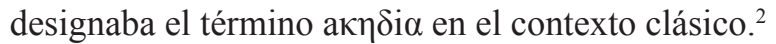

Esta conceptualización realizada por Evagrio resulta - ligada como está al abundante contenido psicológico de sus obras — del mayor interés para la psicología y la psicopatología. Esto ha sido puesto de manifiesto por diversos estudios actuales como los citados de Bernard Forthomme, y también los de Angelo Gianfrancesco (2008), Francesco Palleschi (2005), Jean-Nicolas Despland (2013), Giorgio Agamben (2002), María Lucrecia Rovaletti y Martín Pallares (2014), Lucrèce Luciani-Zidane (2009), Rubén Peretó Rivas (2010; 2011a; 2013), entre otros.

${ }^{2}$ El origen del término acedia se encuentra en la locución griega $\alpha \kappa \eta \delta \varepsilon \tau \omega \varsigma$ que es, como

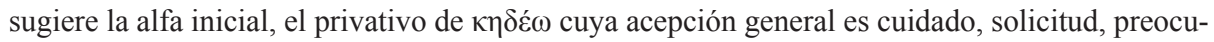
parse por algo o alguien. Su significado primario es, por lo tanto, falta de cuidado o incuria. En este sentido es usado, por ejemplo, por Platón en Leyes ("Pero si alguien no cuida ( $\alpha \kappa \eta \delta \eta \varsigma)$ a sus hijos,..." [XI, $913 \mathrm{c}]$.$) . No obstante, el término es usado también, entre los griegos, con un$ sentido más preciso y de mayor implicancia filosófica. Él designa una falta especial de cuidado, una despreocupación o incuria singularísimas que los griegos creen menester especificar pues no se trata de una despreocupación cualquiera. La incuria que designa este término tiene que ver con la existencia misma y con cómo ésta es afrontada y vivida. Aкŕ $\delta \varepsilon \tau \omega \varsigma$ es, en fin, falta de interés o de cuidado por la sepultura, renuncia al duelo, ausencia de ritos funerarios, despreocupación ante la muerte. En este sentido es usada, por ejemplo, por Homero: "No me ofrezcas asiento, criatura

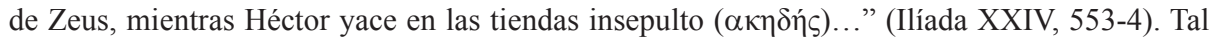
despreocupación resulta para los griegos de una inusitada gravedad. Como indica Forthomme, los griegos adivinan en esta despreocupación, expresada en la incapacidad de guardar duelo, una hesitación dramática acerca de la propia identidad, una angustia manifiesta en cuanto al propio origen, naturaleza, ambiciones y destino (Forthomme, 2005). La utilización, recogida por Forthomme, que hace Empédocles de nuestro término expresa claramente esta idea. El mismo designa para el presocrático un espíritu despreocupado de sí mismo. Se trata, en suma, de una despreocupación - la que se refiere a los difuntos — que manifiesta una incuria del hombre respecto de sí mismo, incuria por la cual se oblitera la dimensión especular de la muerte. El despreocupado griego es aquel que no sólo no sabe quién es sino que ha perdido el interés por saberlo. 
Ciertamente no se puede - sin traicionar su pensamiento - obviar la presencia, en la exposición evagriana, de una perspectiva espiritual de fuerte contenido cristiano. Evagrio, en efecto, escribe en el contexto del primer monacato cristiano, él mismo es monje y su obra está destinada principalmente a monjes. Los ocho pensamientos de Evagrio (logismoi) — pieza maestra de su doctrina, antecedente más antiguo de la lista de los pecados capitales y muestrario de la riqueza psicológica de sus análisis — se identifican, son generados o profundizados por los demonios. Éstos introducen - en el mar de la imaginación - palabras o imágenes precisas que desencadenan un torrente de pensamientos que trastornan al monje. Esta apelación a los demonios podría llevar a concluir apresuradamente que se trata, una vez más, de una concepción primitiva y supersticiosa de la enfermedad psíquica. Digamos que hay, efectivamente, en Evagrio una perspectiva espiritual que transforma el análisis de los padecimientos psíquicos que se observan. No obstante, ello no hace perder inteligibilidad etiopatogénica a los análisis evagrianos, ni merma la sutileza de sus observaciones psicológicas. El análisis de los procesos psíquicos y las conclusiones que en este campo se alcanzan se complementa naturalmente en el pensamiento de Evagrio con la apelación a un mal personalizado que promueve o profundiza, mediante el lenguaje, diversos padecimientos. Al margen del interés estrictamente psicológico que posee la afirmación de que el trastorno procede del lenguaje, resulta oportuno evocar aquí lo sostenido por dos estudiosos del pensamiento evagriano, el alemán Gabriel Bunge y el argentino Peretó Rivas, respecto a la apelación a los demonios. Ello no constituye para estos dos autores un rasgo de mentalidad primitiva que obscurece las importantes intuiciones psicológicas presentes en la obra evagriana. Por el contrario, la profundidad psicológica del análisis del monje del Ponto - y en general de los Padres del desierto - está vinculada directamente a esta concepción cósmica y metafísica más amplia pues hablar de demonios significa personalizar el mal, nombrarlo, y por lo tanto tomar conciencia de la propia responsabilidad frente al mal. El hombre deja de ser así prisionero de un mal anónimo e inasibley tiene frente a él posibilidad de superación (Bunge, 2007; Peretó Rivas, 2012).

Dicho esto, se entiende lo que ha sostenido recientemente Pérez Rincón (2014) remarcando la importancia que tendría el renovado análisis de la noción de acedia en el marco de la psicopatología. Como ha dicho este autor, nombrar no es una actividad inocente. Llamar acedia a ese padecimiento humano tan singular y tan semejante a la hodierna depresión, implica que Evagrio está entendiendo este perturbación psíquica desde una perspectiva que, sin descartar el minucioso análisis psicológico, asume una dimensión espiritual y metafísica que configura la concepción psicopatológica y la misma propuesta terapeútica, pues también la hay en el pensador del Ponto, como veremos. En efecto, la noción de acedia que 
recoge Evagrio y a la que da, como hemos dicho, una sistematización teórica y una proyección psicológica y espiritual que no existía hasta ese momento, se hallaba en el mundo griego designando confusa pero significativamente la falta de cuidado de la sepultura. Una falta que revelaba un profundo descuido para con el propio ser, una - como ha dicho con acierto Forthomme - duda dramática acerca de la propia identidad (Forthomme, 2005). Este término y su carga conceptual es el que recoge Evagrio para designar el estado de atonía psíquica que observaba.

Teniendo en cuenta entonces toda esta riqueza psicológica y metafísica de la concepción evagriana, intentaremos aquí despejar algunos aportes del monje del Ponto en la comprensión etiológica de ese padecimiento tan cercano a la melancolía moderna y a la depresión contemporánea, que él sistematizó por primera vez: la acedia. Para visualizar la importancia histórica de su aporte y de qué manera éste anticipa planteamientos muy posteriores de la psicopatología, evocaremos brevemente algunos elementos tanto de la comprensión freudiana de la melancolía cuanto de una importante teoría contemporánea acerca de la depresión, la Self-discrepancy theory. Los conceptos propuestos por tales enfoques - de importancia indiscutible en las modernas concepciones psicopatológicas - aparecen claramente en el análisis evagriano y se proyectan en una perspectiva espiritual quetransforma la comprensión etiológica del padecimiento analizado y modela una incipiente propuesta terapeútica de la que haremos sólo algunas breves referencias pues nos interesa aquí centrarnos principalmente en las conceptualizaciones psicopatológicas de Evagrio y su posible confluencia con desarrollos de la psicología contemporánea.

\section{La melancolía, la depresión y el ideal del yo}

Comencemos entonces por detenernos un momento en algunos elementos significativos de aquellos dos abordajes de la psicología contemporánea.No es objeto del presente trabajo desarrollar la teoría freudiana de la melancolía y la de la depresión de Higgins. Sólo nos interesa poner de relieve algunos aspectos de los análisis etiológicos propuestos por tales autores que aparecen significativa y esclarecedoramente en Evagrio Póntico y, como hemos dicho, se proyectan en una teoría profunda acerca de la acedia e incluso en una incipiente propuesta terapeútica.

El concepto que juega un papel clave en las explicaciones etiológicas de la melancolía y la depresión que proponen estos enfoques, es el de "ideal del yo". Ciertamente es un concepto de cuño psicoanalítico pero que encuentra su equivalente conceptual y aún terminológico en el marco de una teoría con gran pregnancia en la actualidad como es la Self-discrepancy theory. 
Freud utiliza por primera vez este concepto en su importante obra Introducción al narcicismo. Volverá sobre ella de modo más sistemático en su no menos relevante ensayo titulado El yo y el ello, y realizará algunas precisiones significativas para nuestro interés en Psicología de las masas y análisis del yo. Digamos rápidamente con Laplanche y Pontalis que el ideal del yo es "la instancia de la personalidad que resulta de la convergencia del narcisismo (idealización del yo) y de las identificaciones con los padres, con sus substitutos y con los ideales colectivos" (Laplanche \& Pontalis, 2004). En efecto, Freud asignará claramente a esta instancia psíquica el rol de sustituto del narcicismo infantil pues sobre él recaerá el amor que en la infancia gozó el yo real. ${ }^{3}$ Este ideal del yo cumple funciones fundamentales en la constitución y desarrollo psíquicos. Es, entre otras cosas, la condición de la represión (mecanismo estructurante del psiquismo en Freud), el responsable de la formación de la conciencia moral y de las categorías valorativas del sujeto, el observador de sí, el censor onírico, el factor causal del sentimiento de culpa, la causa eficiente de los fenómenos de masas y de la constitución de la religión, y muchas más.

Así entendido, este ideal se constituye en una instancia rectora que regula los sentimientos, las aspiraciones y las conductas del sujeto. Por ello Freud dirá en una de sus conferencias de introducción al psicoanálisis que el ideal del yo es el referente psíquico "con el cual se compara el yo, al cual aspira y cuya demanda de perfección siempre creciente se esfuerza en satisfacer” (Freud, 1933[1932]/2013d).

Poseyendo tantas y tan importantes funciones no es extraño que el análisis de su configuración, de su desarrollo y de su acción intrapsíquica sea de primaria importancia en la elucidación de ciertos mecanismos psicopatológicos. Atendiendo a nuestro interés detengámonos por un momento en el rol que desempeñaría al interior del dinamismo etiológico de la melancolía.

$\mathrm{Y}$ aquí nos encontramos con aquellas precisiones, mencionadas más arriba, que realizara el maestro de Viena en la obra "Psicología de las masas y Análisis del yo". Dirá allí que en la melancolía el yo se nos muestra dividido, descompuesto en dos fragmentos, uno de los cuales arroja su furia sobre el otro. El ideal del yo es aquí el victimario. Por lo tanto no es inverosímil suponer, nos dirá el psiquiatra vienés, que

la miseria del melancólico constituye la expresión de una oposición muy aguda entre ambas instancias del yo; oposición en la que el ideal, sensible en exceso,

3 "El narcisismo aparece desplazado sobre este nuevo yo ideal, adornado, como el infantil, con todas las perfecciones" (Freud, 1914/2013b). 


\section{ARTIGO}

manifiesta implacablemente su condena del yo con la manía del empequeñecimiento y de la autohumillación. (Freud, 1921/2013e, p. 2602).

Se trata, en efecto, de un delirio de empequeñecimiento, de insignificancia moral como sostiene el psiquiatra vienés (Freud, 1917[1915]/2013a), determinado por las instancias ideales del yo (Kaufmann, 1996). Se entiende entonces que en la melancolía el paisaje intrapsíquico, como bien indican Magtaz y Tosta Berlinck, se organice sobre un eje vertical: el ideal (altura) y su fracaso (el abismo). En este eje se mueve sin cesar el melancólico, sin salir de la verticalidad (Magtaz \& Berlinck, 2012). Aquel delirio de empequeñecimiento es precisamente lo que distingue la melancolía del estado de duelo, nos indica Freud, y lo que hace sospechar el contenido narcicístico de este padecimiento (Freud, 1917[1915]/2013a).

En efecto, si el ideal es un sustituto del narcicismo y si la melancolía consiste en el fracaso en la consecución de tal ideal, entendemos por qué Freud la sitúa, en su texto de síntesis "Neurosis y psicosis" de 1924, dentro de las psiconeurosis narcisistas. En la base de la melancolía "hay un conflicto entre el yo y el super-yo", constituido este último "por un ideal hacia el que tienden todas las aspiraciones del yo" (Freud, 1924[1923]/2013c). Por ello el famoso temperamento melancólico de los místicos, los revolucionarios, se explica para Roudinesco en la búsqueda de un ideal que siempre se sustrae (Roudinesco, 2008). Bleichmar, por su parte, siguiendo las conceptualizaciones acerca de la melancolía de Freud, identifica claramente en un elevado ideal del yo la predisposición a lo que él llama "depresión narcicística crónica" (Bleichmar, 1980).

Los episodios maníacos que pueden suceder o anteceder, en ciertos cuadros clínicos, a los arrebatos melancólicos son explicados por el fundador del psicoanálisis en continuidad con estos conceptos. En estos estados "el yo y el ideal de yo se hallan confundidos, de manera que el sujeto, dominado por un sentimiento de triunfo y de satisfacción, no perturbado por crítica alguna, se siente libre de toda inhibición y al abrigo de todo reproche o remordimiento" (Freud, 1921/2013e).

Profundizando en las implicancias de estas nociones, el psicoanalista francés Jacques Golberg, señalará que el ideal del yo es una imagen concreta que condensa cualidades llevadas a su perfección. Estar en falta, es estar en falta en relación al ideal. Éste es, en este sentido, criterio psíquico matriz. Y es precisamente de aquellas cualidades perfectas de las que el depresivo se siente absolutamente desprovisto y de las que exige ser provisto absolutamente. Por ello el ideal impone al sujeto una tarea sin límite, imposición que revela su condición tiránica y esclarece la cercanía de la desesperación depresiva con la agitación ansiosa del obsesivo (Golberg, 1985).

Utilizando algunos aspectos de la noción de ideal del yo, tenemos también, como ya lo hemos adelantado, una teoría de importante repercusión en distintos ámbitos de la psicología en la actualidad, la Self-Discrepancy Theory. Esta procura explicar dos patologías fundamentales, la depresión y la ansiedad, a 
partir de discrepancias del sujeto consigo mismo. La teoría fue propuesta inicialmente por el psicólogo norteamericano Edward Tory Higgins hacia 1987. Desde entonces viene siendo analizada y utilizada en diversos ámbitos de psicología. ${ }^{4}$ Digamos sumariamente que esta teoría, partiendo de una concepción motivacional del yo, entiende el malestar emocional como una discrepancia significativa entre los llamados "dominios del yo" que son, a saber, el "Yo real"o autoconcepto, y sus guías: el "Yo ideal" y el "Yo que debería". Estas dos guías son las principales fuentes motivacionales de las personas, nos señala Higgins, y sirven como contexto evaluativo e interpretativo del autoconcepto. Cuando este último, por ej., no se corresponde o no armoniza con lo que la persona quisiera ser, con el estado ideal que él o ella personalmente espera o desea lograr, existe una autodiscrepancia que puede generar, dependiendo de la frecuencia con que ella se activa, sentimientos ligados a la depresión como tristeza, abatimiento y desánimo. Si la reducción de dicha discrepancia no se produce, la desarmonía inicial puede agravarse y convertirse en trastorno emocional; en este caso, en depresión. ${ }^{5}$

\section{La acedia evagriana como metarrealidad. El ideal de perfección}

Vayamos ahora al concepto evagriano de acedia intentado visualizar simultáneamente algunas convergencias temáticas con lo anterior y adentrándonos en algunos aspectos de esta noción relevantes para la psicología y la psicopatología.

Situemos en primer lugar la noción de acedia en el marco de la teoría de los ocho pensamientos de nuestro pensador. Dicha teoría, que constituye el antecedente más remoto de los llamados vicios capitales (Guillaumont, 1971), tiene en nuestro concepto acaso su aporte más original. Si bien cada uno de estos ocho logismoi, como los llama Evagrio, posee características diferenciales, todos proceden de una fuente común: los demonios. Éstos, especificados por los vicios que promueven y peritos en el que los nomina, desencadenan, a partir de una introducción sutil de palabras, un torrente de pensamientos que tiene como objeto alejar al hombre del conocimiento divino (Evagrio Póntico, 1971). Ciertamente,

${ }^{4}$ Cf., por ejemplo, Michael Kernis (2006); Ayoung Suh (2013); Jinkyung Na, Incheol Choi \& Sunhae Sul (2013); Serena Chen, Helen C. Boucher, Susan M. Andersen \& Adil Saribay (2013), entre otros.

${ }^{5}$ Para más precisions remitimos a: Edward Tory Higgins (1987); Timothy Strauman (1996); Jennifer Boldero, Marlenne Moretti, Richard Bell \& Jillian Francis (2005). 
estos pensamientos poseen un factor causal concurrente de naturaleza psíquica y una manifestación afectiva y conductual que son tematizados por Evagrio y que resultan del mayor interés a la psicología y a la psicopatología. Por lo demás, resulta significativo que aquellos demonios actúen por medio del lenguaje y que sea por medio del lenguaje que consumen su acción desestabilizadora de la psiquis. Los demonios, en efecto, "han aprendido el lenguaje de los hombres" y es en el lenguaje interior del hombre, el nous y sus pensamientos, donde concretan su ataque (Evagrio Póntico, 1958). Ellos soplan palabras al oído, indica gráficamente Evagrio (2005). El lenguaje posee en el pensador del Ponto un potencial patógeno cuyo negativo es su virtualidad curativa.

En la descripción que realiza el Póntico del desarrollo de la acción de estos pensamientos aparece, con distintas modulaciones, una verdadera explicación psicológica de los estados afectivos desencadenados por aquéllos y desencadenantes de aquéllos. Estos logismoi son entendidos, no simplemente como sugestiones diabólicas, sino como representaciones imaginarias o ideas procedentes de las pasiones y generadoras de pasiones ${ }^{6}$ que pueden, en este sentido, constituir instancias psíquicas - ciertamente aprovechadas para Evagrio por el espíritu tentador - que se transforman en un obstáculo a vencer en la primera etapa de la vida cristiana - la praktiké - y que hasta pueden resultar patógenas. La apelación a una realidad preternatural para explicar el origen de los logismoi, se complementa naturalmente en el pensamiento de los Padres del desierto con una comprensión psicológica que incluso en algunos casos prescinde de aquella apelación.

El caso de la acedia es paradigmático. Se trata de un estado muy próximo a lo que actualmente conocemos como depresión. El demonio de la acedia, actuando sobre una condición psíquica caracterizada por la falta de tono del alma

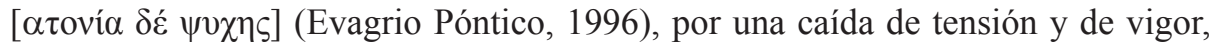
introduce palabras o imaginaciones que pueden desastabilizar al monje e incluso llevarlo a la locura "destrozando su alma"dice sin ambages nuestro filósofo del

${ }^{6}$ Evagrio plantea en el capítulo treinta y siete de su "Tratado Práctico" la discusión referente a la prioridad temporal entre las representaciones y las pasiones. Esta es una cuestión que aparece con frecuencia en su obra (a veces a favor de la prioridad de los logismoi, a veces de las pasiones) y que remite a una discusión presente en la psicología cognitiva del siglo XX. En efecto, en el comentario a aquel capítulo, Guillaumont señala que una de las opiniones que aquí está considerando Evagrio, es la estoica; y cita a continuación aquel aforismo de Epicteto que Albert Ellis transformó en santo y seña de su terapia racional-emotiva, a saber, "Lo que trastorna a los hombres, no son las cosas mismas, sino las opiniones que ellos se hacen de las cosas". 
desierto (1971). ${ }^{7}$ De acuerdo a lo señalado por Evagrio, el tentador opera muy sutilmente, logra colarse, como dice Forthomme (2000), por los intersticios de la vida del monje. De esta manera, puede construir en la mente de éste una "metarrealidad autorreferencial" (Palleschi, 2005). El Póntico define en otro lugar los logismoi como "la representación de un objeto sensible que pone en movimiento a la irascibilidad y a la concupiscencia en un sentido contrario a la naturaleza" (Evagrio Póntico, 1952). Son representaciones que, como tales, se colocan en lugar de la realidad.

Ahora bien, autores contemporáneos como Francesco Palleschi, André Louf y Peretó Rivas, entre otros, han propuesto comprender la acedia en el marco de lo que llamaremos, con el segundo de estos autores, "ideal de perfección" (Louf, 1986). Precisamente la expresión "metarrealidad autorrefencial" es la que usa Francesco Palleschi para designar dicha instancia. Rápidamente encontramos en la expresión "ideal de perfección" un eco de la terminología freudiana. Veremos que dicho eco es expresión de una confluencia conceptual más profunda.

Los análisis que - siguiendo las intuiciones evagrianas — nos presentan los tres autores mencionados tienen la ventaja de ofrecernos fotografías de la acedia. Son, respecto a la acedia, lo que en psicopatología se llamaría análisis de caso. Palleschi y Peretó Rivas, en efecto, realizan sendos análisis de monjes famosos del siglo XII. De Adam Scott,canónigo premostratense en la abadía escocesa de Dryburgh y luego monje cartujo, el primero (Palleschi, 2005); y de Hugo de Miramar, archidiácono de Maguelone y también posteriormente monje cartujo, el segundo (Peretó Rivas, 2013). André Louf, por su parte, presenta diversos apotegmas de los padres del desierto.

Los casos de Adam Scott y Hugo de Miramar son paradigmáticos de los llamados transitus monásticos ocurridos hacia el siglo XII. Se trata de pasajes de un estado de vida a otro más riguroso, en el que aparentemente se podrá alcanzar la anhelada perfección. Estos pasajes están precedidos de profundas crisis

${ }^{7}$ Aquella atonía con que Evagrio define a la acedia (1996) es confluyente con la "anestesia psíquica” con que Kaufmann define a la melancolía psicoanalítica. Una tal anestesia se manifiesta, por ejemplo, en la incapacidad del acedioso de verter lágrimas, en su torpor generalizado, en su apatía frente a las actividades monásticas.La realidad que al melancólico le es definitivamente hostil al acedioso le produce aversión y odio pues todo parece estar signado por ese sinsentido de que habla Kaufmann. El futuro es oscuro como lo fue el pasado, "largos años de vida amarga" restan, entre pobrezas y enfermedades y, en fin, cualquier tipo de esperanza es derrumbado (Kaufmann, 1996; Evagrio Póntico, 1971, 1996, 2005). 


\section{ARTIGO}

melancólicas, las cuales persisten una vez consumado el tránsito. En todos los casos se trata de una búsqueda febril de la perfección.

Louf, por su parte, acuña el concepto de ideal de perfección para designar esa verdadera instancia psíquica que demanda al religioso trabajar sin descanso para adecuar su yo a un ideal de perfección preconcebido. Dicho ideal enferma al monje y lo enloquece hasta el punto de pensar, por ej., que por el mérito de sus virtudes y trabajos, por haber llegado a fusionarse a su ideal de perfección, podría salir indemne después de precipitarse a un pozo, como relata Casiano que le sucedió al anciano Herón (Casiano, 2008). Resulta significativo el texto de la Sagrada Escritura que, sin más, evoca Evagrio para rechazar el logismos que engaña al monje susurrándoleal oído que ha logrado la perfección. Se trata del fragmento del Eclesiastés que reza: "Es mejor un perro vivo que un león muerto" (Evagrio Póntico, 2005). Nuestro monje podría estar recordando aquí al anciano Herón. En efecto, en el capítulo veintitrés de su tratado sobre los pensamientos (1998a) y en el diecisiete del su "Ocho espíritus de la maldad" (1996), realiza una descripción detallada del desequilibrio psíquico y el hundimiento final en la locura en que se puede caer a causa de los pensamientos de orgullo y hace referencia, en el primero de los tratados, a dos hermanos suyos en la vida monástica cuyo naufragio mental está siempre aleccionadoramente bajo sus ojos. Guillaumont (1971) señala, comentando este pasaje, que muy probablemente Evagrio está haciendo referencia aquí a dos monjes de los que habla el discípulo y biógrafo de monje del Ponto, Paladio, en su Historia Lausíaca. Estos dos monjes son Valens y Herón. Por lo demás, Casiano es contemporáneo y discípulo de Evagrio y es este último una de sus principales fuentes (Pichery, 2008).

Aquel orgullo o soberbia desequilibrante - fundada en la necesidad de enaltecer y exaltar al propio yo lo cual en Evagrio es la esencia de la vanagloria - es la que lleva al monje a creer que ha alcanzado la perfección, que ha subido hasta una gran altura, que él es la causa de muchas buenas acciones y que el resto le debe reconocimiento por ello (Evagrio Póntico, 1971; 1996). Aquella necesidad de exaltar al yo que lleva a imaginar y a proyectar determinadas situaciones en las que el propio yo es enaltecido y alabado, deviene - a partir de una práctica ascética cuya excesiva e imprudente rigurosidad, condenada por Evagrio,evoca mucho las conductas maníacas - en una creencia irracionalconsistente en la certeza de que se ha alcanzado por las solas fuerzas, como lo mostrarían las prácticas y los hábitos diarios de ascetismo riguroso y piedad profunda, la perfección. Alcanzado este endiosamiento se está, por lo mismo, incluso más allá de las leyes de la naturaleza. Tirarse a un pozo y salir indemne lo probaría. Aquella condición irremediable y definitiva que Evagrio ve en el naufragio del orgullo, se muestra patentemente en el caso de Herón el cual persiste en su delirio 
de grandeza, aún moribundo durante los dos días que duró su agonía (Casiano, 2008). Por eso Evagrio propone frente al pensamiento "que me exalta como si hubiera alcanzado la perfección en la práctica de los mandamientos" o "como si en mi mente no hubiera huella de pecado", la meditación de textos de la Escritura que muestren el engaño demoníaco que significa creerse perfecto y sin huella de pecado (Evagrio Póntico, 2005).

Frente a la historia de Herón no podemos sino recordar la explicación delos episodios maníacos que nos ha ofrecido Freud y que hemos citado brevemente más arriba. Se trata, señala reveladora y convergentemente Louf, de una "imagen narcisista de la propia perfección" (Louf, 1986) que atrapa al monje, le demanda tareas y rigores ascéticos imprudentes, y es fuente tanto de desánimo permanente - pues el religioso no cesa de compararse y de medirse con su ideal y de verificar cuán lejos está de él - , cuanto de, en ocasiones, episodios maníacos como el de Herón en el cual evocamos la explicación freudiana explicitada más arriba.

El análisis de este ideal de perfección o metarrealidad autorreferencial, tematizado por Evagrio, nos pone frente al operar de una instancia psíquica en la vida espiritual de los monjes. En este contexto la acedia se revela - en la tematización evagriana - en su relación causal con el logismos de la vanagloria, pues aquel ideal es construcción de este pensamiento. Y ciertamente dicha relación causal nos remite inmediatamente a la existente entre la melancolía y el narcisismo.

El ideal de perfección se nos descubre como una - y usemos la expresión precisa de Palleschi — "construcción metarreal de la vanagloria" que da lugar a las ficciones, la desesperanza y el abatimiento de la acedia. Y es que dicho ideal, constituyendo una instancia tiránica con demandas ilimitadas como se ha referido Golberg al ideal del yo (Golberg, 1985), se manifiesta continuamente discrepante con la realidad actual del yo.

Después de describir las ficciones que introducen las palabrasdel demonio de la vanagloria, en virtud de las cuales el monje se imagina en un estado de santidad en el que todos reconocen su perfección y virtud, Evagrio subraya que este espíritu malvado, cumplido su cometido de exaltar al anacoreta con vanas esperanzas, lo abandona a la desesperanza. Probablemente presentándole, luego de la exaltación, su presunto estado actual, tan alejado de esa santidad en la que se imaginaba "el que, un instante antes, era un santo sacerdote" (Evagrio Póntico, 1971). El demonio introduce un espejismo, una metarrealidad en la que el yo es exaltado. Ciertamente la condición de posibilidad de esta acción intrapsíquica del tentador - y notemos aquí el rol primario del elemento psíquico en la génesis de los trastornos que producen los pensamientos - consiste en una conformación pasional que en términos evagrianos se denomina philautía ( $\varphi \imath \lambda \alpha v \tau i ́ \alpha)$ o amor por sí mismo el cual viene a ser en Evagrio como la matriz de todos los logismoi (Evagrio Póntico, 1998a; Bunge, 2008; Guillaumont, 2009). Este concepto es 
equiparable, como lo ha señalado Larchet, al contemporáneo de narcicismo, de origen psicoanalítico pero incorporado al conjunto de la psicología denominando incluso un trastorno de la personalidad tipificado por el actual Manual diagnóstico y estadístico de los trastornos mentales, o DSM IV. Tal equiparación refuerzael paralelo entre el ideal del yo freudiano - producto del narcisismo - y el ideal de perfección que aliena al monje y que Evagrio vincula causalmente a la vanagloria $\mathrm{y}$, en general, a la philautía.

Ahora bien, perseguiendo aquel espejismo que el demonio evagriano ha creado con la dúctil materia de las representaciones pasionales, el monje nota una discrepancia abismal entre su yo real y su yo ideal. La melancolía o depresión que, como hemos visto, constituía para Freud y Higgins el resultado una discrepancia tal, aparece también en el análisis de Evagrio Póntico bajo los términos de tristeza y acedia - dos logismoi que Larchet llama vecinos y que son muy semejantes en su manifestación sintomatológica y en su dinamismo etiológico de tal manera que, algunos siglos después, San Gregorio Magno y Santo Tomás de Aquino sostendrán que la acedia es un tipo de tristeza - , como resultado de un itinerario cognitivoafectivo idéntico. Larchet, quien reconduce el trastorno depresivo de la psiquiatría contemporánea a la tristeza y a la acedia de los Padres del desierto, sostiene en este sentido: "La tristeza puede tener por causa una decepción en la búsqueda de honores, y parece pues necesariamente ligada a la vanagloria (...) Hemos notado, estudiando la pasión del tristeza, el lazo estrecho que ella guarda con la pasión de la vanagloria. La decepción en la búsqueda de los honores y la gloria en este mundo es una causa frecuente de tristeza" (Larchet, 2002).

Palleschi señala que existe un autodiálogo, con "el otro de sí mismo", que puede ser promotor de acedia. Ahora bien, este otro de sí mismo con el que, según Palleschi, el monje entra en diálogo, puede corresponderse a las guías del yo de Higgins. En efecto, el otro de Palleschi reprende al monje Scott, le presenta la imperfección de su vida actual, la posibilidad de buscar un estado de vida en el que la perfección sea asequible. Se transforma para él, como el yo ideal de Higgins, en guía interpretativa, en norma evaluativa, en criterio de decisión. Se entiende entonces que Larchet afirme, por su parte, que la depresión que él identifica con la tristeza y la acedia, tenga como posible factor "el valor que nosotros pensamos tener a nuestros propios ojos y a los ojos de otros" (Larchet, 2002). Dicha autovaloración se realiza en función del ideal, inalcanzable para el depresivo, ideal que ciertamente, como también lo afirma Higgins, ha sido forjado, en parte, por los otros significativos del entorno.

Por otra parte, esta autovaloración en función del ideal la podemos interpretar a la luz de aquella "capacidad fantasmática de hacer aparecer como perdido un objeto inapropiable" con que Agamben define a la melancolía freudiana, tan cercana, según su conceptualización, a la acedia patrística y medieval (Agamben, 
2002). En esa autovaloración negativa, en efecto, se busca lograr una posesión del ideal mediante la autodenigración. El ideal se ha vuelto un objeto inapropiable del que sólo me puedo apropiar autodenigrándome. Con la autodenigración me coloco en una posición distinta y más alta a la de aquel yo lejano del ideal. Me acerco más al ideal mientras más duramente cualifique al yo alejado del ideal. Es esta la sutil manera que tiene el yo de sentir que no está tan lejos del ideal. Criticándose y denigrándose participa del ideal anhelado. Acaso sea esta la razón por la que Evagrio, por su parte, reprueba y advierte contra la tristeza procedente de pensar melancólicamente en los pecados del pasado. Una tal tristeza proviene dela vanagloria y del orgullo y debe ser rechazada (Evagrio Póntico, 2005).

Que la sugestión del logismos de la acedia se concrete hacia la hora sexta como señala Evagrio (1971), es un dato no menor. El mediodía es la mitad de la jornada, cuando el trabajo y la ascesis pesan por el calor y el ayuno, y aún restan muchas horas para que el día termine. El objetivo está lejos y el monje no se ve capaz de sostener su tensión durante todo el día y, por extensión imaginaria, durante toda la vida. El tentador aprovecha esta situación representándole los objetivos inalcanzables de la vida emprendida, profundizando así la desazón y configurando en el estado de ánimo del monje una esencial insatisfacción con todo, una disconformidad con la realidad en general. Al darse cuenta que no es perfecto, al compararse con aquel ideal obsesivo que ha introducido el demonio de la vanagloria, experimenta desgano por la vida emprendida, abatimiento.

Louf presenta hacia el final de su artículo un significativo apotegma protagonizado por San Jerónimo en el que aparece lo que acaso sea el objetivo final de la acedia evagriana: la tentación de "abandonar [la] celda y [huir] del estadio" (Evagrio Póntico, 1971). El joven monje que era Jerónimo en ese momento atraviesa una profunda crisis por la cual, indica el apotegma, "había perdido el ánimo y estaba a punto de abandonarlo todo" (Louf, 1986). Es interesante observar que Jerónimo es, en ese momento, un joven que, buscando una perfección preconcebida que el mismo Jesucristo — apareciéndosele — se encargará de desarticular, se ha entregado a una vida de soledad y rigor ascético. Contemplando el ulterior proceso de Jerónimo a la luz de las conceptualizaciones evagrianas se entiende que el monje del Ponto sostenga en su "Antirrhético" que la tentación de morar en la soledad en los jóvenes es característica de la vanagloria (Evagrio Póntico, 2005). En efecto, aquel desánimo y sugestión propias del demonio de la acedia, aparecen en Jerónimo encadenadas causalmente a una dolorosa comprobación: seguía experimentado antiguas tentaciones de las que había pensaba que su esfuerzo ascético lo libraría, y no obtenía la respuesta del cielo que dicho esfuerzo, al parecer, merecía (Louf, 1986). Las tentaciones son para él el indicio de que se halla lejos de la perfección que con tanto esfuerzo ha perseguido y para la cual se ha entregado a una vida en soledad. Si tenemos 
en cuenta la exégesis evagriana, no nos resulta difícil adivinar que este joven monje ha caído en las redes del demonio de la vanagloria. Este espíritu malvado lo exalta primero con la imagen de su propia perfección y lo empuja a ponerse en camino hacia ella, "a rivalizar con Juan Baustista" (Evagrio Póntico, 1998a), para colocar después ante sus ojos - consumada ya la sedimentación psíquica de aquellas categorías - las circunstancias de su vida que evidenciarían lo lejos que se halla de esa perfección. Como afirma Palleschi, la realidad creada por el demonio tiene, en tanto creación del lenguaje, su propia gramática. En el marco de esa realidad resulta evidente que experimentar cierto tipo de tentaciones es signo inequívoco de fracaso en la búsqueda de la perfección. En el apotegma no se nos especifica cuáles eran esas "antiguas tentaciones" que caían sobre Jerónimo, pero teniendo en cuenta el desaliento que generan en él, se entiende que se trata de tentaciones sexuales que hacen evidente - repetimos: evidente en el marco de esa realidad sutilmente ficticia que las palabras del tentador han creado en él — su lejanía respecto de la anhelada perfección. En efecto, de acuerdo a Evagrio Póntico (1971), el pensamiento de la vanagloria, después de haber exaltado a su víctima, lo abandona también al demonio de la lujuria.

Aquel ideal se transforma entonces en el criterio matriz de la mente, en la luz bajo la cual las cosas se manifiestan. Con él evalúa el monje su estado de vida y lo reprueba. Con él examina a los demás y llega a afirmar: "la caridad ha desaparecido en los hermanos" (Evagrio Póntico, 1971). Esta instancia actúa como las guías del yo de Higgins que son también, por su parte, criterios en la evaluación de los otros (Higgins, 1987).

Es atendiendo a las trampas que puede tender esta instancia psíquica instrumentalizada por el demonio, que Evagrio previene e instruye acerca de un posible ayuno desmedido, señalando, que una tal desmesura es siempre incitada por el demonio. En algunos de los ejemplos que pone al referirse a este tópico, adivinamos de qué manera el ideal de perfección es vinculado por este lenguaje demoníaco a determinados comportamientos compulsivos a que se ve constreñido el monje alienado por el ideal: un monje perfecto, en efecto, debe, aún enfermo gravemente, practicar la abstinencia y salmodiar de pie, o hacer juramentos de ayuno, o atar pesos a las caderasy adentrarse en el desierto viviendo a cielo abierto huyendo de la vista de los hombres y comiendo raíces salvajes (Evagrio Póntico, 1971; 2005). Tales sugestiones cognitivas son identificadas con precisión por Evagrio y desarticuladas mediante la oposición depalabras apropiadas de la Sagrada Escritura que pongan en evidencia su carácter ficticio e irracional. Como la Sagrada Escritura constituye, en el mundo monástico, la instancia suprema de referencia y el fundamento mismo de la vocación escogida, su mensaje posee una fuerza y una repercusión afectivas capaces de rechazar un pensamiento obsesivo o socavar una creencia irracional. Por lo demás, en este que es el método evagriano 
para combatir los pensamientos malvados — el llamado método Antirrhético - se ve el arte de Evagrio para desbrozar el mundo de los pensamientos, identificar clara y concisamente aquellos que pueden perturbar al monje y oponerle una palabra precisa en la cual el monje contemple, a la vez, el carácter ficticio del pensamiento perturbador y la posibilidad de apropiarse de otro modo de significar y pensar las situaciones de su vida. A este respecto resulta del mayor interés poner en relación el modo que tiene Evagrio de comprender la virtualidad curativa de la palabra, con algunos estudios actuales acerca de los patrones lingüísticos que subyacen a los momentos de cambio en un proceso psicoterapeútico. En otro lugar nos hemos ocupado de esta posible vinculación (Vazquez, 2013).

De modo que, teniendo en cuenta aquellas sugestiones engañosas, Evagrio dirá que la ascesis del monje no tiene que ser espectacular sino siempre igual e incluso habrá ocasiones en que el monje esté eximido de cumplir la regla prescrita. El demonio de la vanagloria inspira, por la magnetización hipnotizadora del ideal, un trabajo ascético imprudente que puede llevar al desequilibrio. Por lo que resulta necesario mantener el ayuno y las prácticas ascéticas siempre iguales y tener la sabiduría de conformar su ejercicio a las circunstancias.

En la novela de DostoievskiLos hermanos Karamazov, el monje Theraponte, paradigma del religioso alienado por el ideal de perfección, reclama al piadoso starets Zosimo no cumplir en toda ocasión con la regla prescrita, y esto es para él prueba irrecusable de que Zosimo no es un santo sino un glotón, hospedero del demonio. La perfección implica cierto tipo de comportamientos incompatibles con los que realiza Zosimo, y de los que él — Theraponte — es ejemplo. La locura final de este último guarda una notable semejanza con la que, según Evagrio, aqueja al monje orgulloso que llegó a identificarse con su ideal de perfección.

Por otro lado, resulta significativo que este ideal sea, como hemos visto, construcción metarreal del demonio de la vanagloria y que la identificación con él posibilite la acción desequilibrante del demonio del orgullo. Esto no está alejado del dinamismo con el que explica Freud el ideal del yo. Éste es, como ya lo hemos señalado, hechura del narcicismo y su identificación con él produce el éxtasis del sujeto "dominado por un sentimiento de triunfo y satisfacción" (Freud, 1921/2013e). La vanagloria y el orgullo, en efecto, pueden entenderse como consecuencia de una configuración pasional narcicística, buscando la primera y consumando el segundo, la autoexaltación.

El Narciso del mito, como los monjes que corren tras las representaciones de la perfección, se precipita en la fuente que le devuelve su imagen ideal, y es allí donde encuentra la muerte. De igual modo la acedia, a la que vemos aparecer en ligazón causal con la vanagloria, puede destruir al alma del monje "en pedazos como un perro descuartiza a un joven ciervo" (Evagrio Póntico, 1971), acarreando su muerte. 


\section{ARTIGO}

\section{Conclusión}

Hemos observado entonces a lo largo de la presente comunicación, que las semejanzas fenomenológicas entre la acedia y la melancolía y depresión contemporáneas pueden ser reconducidas, en algunos casos, a dinamismos psicológicos comunes. Dimos cuenta brevemente de algunas categorías de la psicología contemporánea que expresan realidades que fueron, en algunas ocasiones intuídas y en otras francamente sistematizadas, por los Padres del desierto, especialmente por Evagrio Póntico. Nuestro análisis, pretendiendo realizar un aporte desde la psicología a la intelección de un fenómeno del ámbito monástico como es la acedia, ha podido despejar algunos elementos psicológicos de ésta procurando, de acuerdo a la oportuna advertencia de Peretó Rivas, "no psiquiatrizar un hecho espiritual" (Peretó Rivas, 2010) pero intentando avanzar en la elucidación de la acción de ciertas instancias psíquicas tematizadas por Evagrio. Adentrarse en dicha tematización ha significado visualizar la rica conceptualización psicopatológica presente en la obra de este pensador de la escuela Patrística y así realizar un aporte, en el marco de los estudios contemporáneos acerca de la acedia, para la reconstrucción histórica de lo que hodiernamente se conoce como depresión. En Evagrio Póntico, en efecto, se hallan muchas ideas y desarrollos psicológicos que reaparecen en las conceptualizaciones psicopatológicas de estos últimos siglos. Aquí nos hemos ocupado tan sólo de algunos elementos pero la obra evagriana amerita nuevas aproximaciones desde esta perspectiva. ${ }^{8}$

Por otro lado, y ya en el marco de los estudios más amplios acerca del pensamiento de Evagrio Póntico, hemos podido comprender un nuevo aspecto del concepto de acedia y ahondar en las implicancias que tiene para Evagrio la primera etapa de la vida cristiana, la praktiké, pues es en el contexto de dicha etapa que estas instancias, potencialmente patógenas, poseen, en tanto formaciones pasionales, una gravitación importante en la vida del monje. La impasibilidad que busca la practiké no es, en efecto, la destrucción de las pasiones sino el estado por el cual ya no les es posible a éstas gravitar decisivamente en la vida espiritual. El impasible es para Evagrio el que ha alcanzado la salud del alma, puesto que - digamos en esta dirección — se ha librado de la esclavitud de los

${ }^{8}$ Por ejemplo, indagando en las notables confluencias con el análisis freudiano de los sueños (Evagrio Póntico, 1971; 1998a), o en la presencia de la noción de esquema corporal (1998a). Asimismo la minuciosa descripción evagriana de pensamientos patógenos amerita un análisis comparativo con los desadaptativos o irracionales de las escuelas cognitivas, como así también las técnicas propuestas para la supresión detales pensamientos. Estos son sólo algunos ejemplos. 
complejos psíquicos cognitivo-afectivos. Por ello la Praktiké es para Evagrio una verdadera terapia o "terapeútica del alma" (Guillaumont, 2009) que busca mediante, entre otras cosas, el autoanálisis, la palabra reveladora del pensamiento escondido y el diálogo fluído con el Abbas (monje anciano, padre espiritual) curar el padecimiento o la enfermedad del alma sometida a los complejos de su afectividad narcisista, en el lenguaje evagriano gobernada por la philautía. La confesión de absolutamente todos los pensamientos al Abbas - quien, por su parte, ejerce en este contexto la función de verdadero terapeuta - incluso de los más recónditos y vergonzantes, resulta el método por excelencia para reconocer la acción alienante del ideal de perfección y curarse mediante la certeza - que el Abbas trasmite - del amor divino al pecador. Esta confesión, preconizada por Evagrio principalmente en su carta a Eulogio (2006), permite una tal curación pues, como se señala Lucio Coco en su introducción a dicha obra, reconoce como propia la parte oscura y negativa de sí, la repone al juego interno del alma y así logra disolver la pesadez de los pensamientos de frustración y culpa que la atormentan pues los asume con la certeza espiritual del perdón de su pecado y del amor divino al pecador. Si como indica Kaufmann (1996) en su conceptualización de la melancolía psicoanalítica, el melancólico enferma por estar, en su delirio autodenigratorio, más cerca de la verdad, para la perspectiva espiritual de Evagrio el acedioso se cura cuando acepta - situado en la certeza del amor divino que lo ha redimido y lo redime en el presente - la verdad acerca de sí mismo y se libera así de su deseo narcisista de ser perfecto.

\section{Referencias}

Agamben, G. (2002). Estancias. Madrid: Editora Nacional.

Bettiolo, P. (2009). Discernimento dei pensieri e conoscenza del cuore. Natura e sovrennatura nell'insegnamento di Evagrio Pontico. Rivista di Storia del Cristianesimo, 6, 43-63.

Bleichmar, H. (1980). La depresión: un estudio psicoanalítico. Buenos Aires: Ediciones Nueva Visión.

Boldero, J.; Moretti, M.; Bell, R., \& Francis, J. (2005). Self-discrepancies and negative affect: A primer on when to look for specificity, and how to find it. Australian Journal of Psychology, 57(3), 139-147.

Bouvier, D. (2005). La fascination du cadavre dans la poésie homérique. In M. Gilbert. Antigone et le devoir de sépulture (pp. 29-49). Genève: Labor et Fides.

Bunge, G. (2007). Akèdia. La doctrine spirituelle d'Évagre le Pontique sur l'acédie. Bégrolles-en-Mauges: Abbaye de Bellefontaine. 
Bunge, G. (2008). Notas al capítulo 6. En Evagrio Póntico. Trattato Pratico. Cento capitoli sulla vita spirituale (pp. 79-82). Magnano: Qiqajon.

Bunge, G. (2009). Encore une fois: Hénade ou Monade? Au sujet de deux notions-clés de la terminologie technique d'Évagre le Pontique. Adamantius, 15, 9-42.

Casiano, J. (2008). Conférences I-VII. Trad. y notas Dom Eugène Pichery. Paris: Les éditions du Cerf.

Casiday, A. (2013). Reconstructing the theology of Evagrius Ponticus. Cambridge: Cambridge University Press.

Cataldo, G. (2007). Vita come tensione nell'antropologia di Evagrio Pontico. Bari: Ecumenica Editrice.

Chen, S.; Boucher, H.; Andersen, S., \& Saribay, A. (2013).Transference and the Relational Self. Recuperado el 8/10/2014 de <http://static.squarespace.com/static/50f6f44le4b08191027c661d/t/51663d98e4b0f61ca30cbd61/1365654936467/Chen\%20et\%20 al.\%202013\%200xford\%20Handbook\%20of\%20Close\%20Relationships.pdfs.

Despland, J.-N. (2013). La tristesse en présence de Dieu: de l'acédie à la mélancolie. Psychothérapies, 33, 71-80.

Evagrio Póntico (1952). Evagriana syriaca: textes inedits du British Museum et de la Vaticane. Ed. J. Muyldermans. Louvain: Université de Louvain.

Evagrio Póntico (1958). Kephalaia Gnostica. Ed. y Trad. Antoine Guillaumont. Paris: Patrologia Orientalis. T. XXVIII, fascicule 1.

Evagrio Póntico (1970). The Praktikos: Chapters on Prayer. Kentucky: Cistercian Publications.

Evagrio Póntico (1971). Traité pratique ou le moine. Tomo II. Ed. y Trad. Antoine Guillaumont y Claire Guillaumont. Paris: Cerf.

Evagrio Póntico (1987a). Praktikos and On Prayer.Oxford: Faculty of Theology.

Evagrio Póntico (1987b). Scholias aux Proverbes. Ed. y Trad. Paul Géhin. Paris: Cerf.

Evagrio Póntico (1993). Scholias a l'Ecclésiaste. Ed. y Trad. Paul Géhin. Paris: Cerf.

Evagrio Póntico (1996). Gli otto spiriti della malvagità. Ed. y Trad. Francesca Moscatelli. Milano: San Paolo.

Evagrio Póntico (1998a). Sur les pensées. Ed. y Trad. Paul Géhin, Antoine Guillaumont y Claire Guillaumont. Paris: Cerf.

Evagrio Póntico (1998b). Trattato Pratico sulla vita monástica. Trad. y notas Lorenzo Dattrino. Roma: Città Nuova.

Evagrio Póntico (1999). La preghiera. Trad. y notas Vicenzo Messana. Roma: Città Nuova.

Evagrio Póntico (2005). Contro i pensieri malvagi. Antirrhetikos. Ed. y Trad. Valerio Lazzeri. Magnano: Qiqajon.

Evagrio Póntico (2006). A Eulogio. Sulla confessione dei pensieri e consigli di vita. I vizi opposti alle virtù. Trad. y notas Lucio Coco. Milano: San Paolo. 
Evagrio Póntico (2008a). Le gnostique ou a celui qui est devenu digne de la science. Ed. y Trad. Antoine Guillaumont y Claire Guillaumont. Paris: Cerf.

Evagrio Póntico (2008b). Trattato Pratico. Cento capitoli sulla vita spirituale. Trad.y notas Gabriel Bunge. Magnano: Qiqajon.

Evagrio Póntico (2009). Talking back.A monastic handbook for combating demons. Kentucky: Cistercian Publications.

Evagrio Póntico (2010). Sentenze. Gli otto spiriti della malvagità. Trad. y notas Lucio Coco. Roma: Città Nuova.

Forthomme, B. (2000). De l'acédie monastique à l'anxio-dépression: histoire philosophique de la transformation d'un vice en pathologie. Paris: Synthélabo.

Forthomme, B. (2003). L'acédie, la dépression, la mélancolie et l'ennui. In G. Charbonneau, \& J. M. Legrand.Dépressions et paradépressions (pp. 21-26). Paris: Le Cercle Herméneutique.

Forthomme, B. (2005). Émergence et résurgence de l'acédie. In N. Nabert. Tristesse, acédie et médecine des âmes dans la tradition monastique et cartusienne: anthologie de textes rares et inédits, XIIIe-XXe siècle (15-35). Paris: Beauchesnes.

Freud, S. (2013a). Duelo y melancolía. In S. Freud. Obras Completas. Tomo 15. Buenos Aires: Siglo Veintiuno editores. (Trabajo original publicado en 1917[1915]).

Freud, S. (2013b). Introducción al narcicismo. In S. Freud. Obras Completas. Tomo 15. Buenos Aires: Siglo Veintiuno editores. (Trabajo original publicado en 1914).

Freud, S. (2013c). Neurosis y psicosis. En S. Freud.Obras Completas. Tomo 20. Buenos Aires: Siglo Veintiuno editores. (Trabajo original publicado en 1924[1923]).

Freud, S. (2013d). Nuevas lecciones introductorias al psicoanálisis. Lección XXXI: Disección de la personalidad psíquica. In S. Freud.Obras Completas. Tomo 23. Buenos Aires: Siglo Veintiuno editores. (Trabajo original publicado en 1933[1932]).

Freud, S. (2013e). Psicología de las masas y análisis del yo. En S. Freud.Obras Completas. Tomo 19. Buenos Aires: Siglo Veintiuno editores. (Trabajo original publicado en 1921).

Géhin, P. (2011). D’Égypte en Mésopotamie: La réception d'Évagre le Pontique dans les communautés syriaques. In F. Jullien, \& M. J. Pierre. Monachismes d'Orient: Images, échanges, influences; hommage à Antoine Guillaumont; cinquantenaire de la chaire des "Christianismes orientaux" (pp. 29-49). Turnhout: Brepols.

Gianfrancesco, A. (2008). Monachisme ancien et psychopathologie. L'evolution psychiatrique, 73(1), 105-126.

Golberg, J. (1985). La culpabilité, axiome de la psychanalyse. Paris: PUF.

Guillaumont, A. (1971). Introduction. In Evagrio Póntico. Traité Pratique ou le moine. Tomo I (pp. 21-125). Paris: Cerf.

Guillaumont, A. (1996). Études sur la spiritualité de 1'orient Chrétien. Bégrolles-enMauges: Abbaye de Bellefontaine. 


\section{ARTIGO}

Guillaumont, A. (2009). Un philosophe au désert. Évagre le Pontique. Paris: Vrin.

Higgins, E.T. (1987). Self-siscrepancy: A theory relating self and affect. Psychological Review, 94(3), 319-340.

Kaufmann, P. (1996). Elementos para una enciclopedia del psicoanálisis. El aporte freudiano. Buenos Aires: Paidós.

Kernis, M. (2006). Self-Steem issues and answers: a sourceboogk of current perspectives. New York: Psychology Press.

Laplanche, J., \& Pontalis, J.-B. (2004). Diccionario de Psicoanálisis. Buenos Aires: Paidós.

Larchet, J.-C.(2002). Le chrétien devant la maladie, la souffrance et la norte. Paris: Cerf.

Louf, A. (1986). Algunas trampas en psicología monástica. Cuadernos monásticos 77 , 193-205.

Luciani-Zidane, L. (2009). L'acédie. Le vice de forme du christianisme. De saint Paul à Lacan. Paris: Cerf.

Magtaz, A.C. \& Berlinck, M.T. (2012). Orality disorders in melancholia: Acedia as Stagnation. Revista Latinoamericana de Psicopatología Fundamental, 15(3), 683-703.

Marchini, D. (2009). La tradizione latina del De Octo spiritibus malitiae di Evagrio Pontico. En G. Heidl, \& R. Somos. Origeniana nona. Origen and the Religious Practice of his Time (pp. 565-575). Pécs: Bibliotheca Ephemeridum Theologicarum Lovaniensium.

Na, J.; Choi, I., \& Sul, S. (2013). I like you because you think in the 'Right' way: Culture and ideal thinking. Social Cognition, 31(3), 390-404.

Palleschi, F. (2005). L'acedie dans l'oeuvre d'un prémontré devenu chartreux au XIIe siècle. Adam Scot et le Liber 'De quadripertito exercitio cellae'. In N. Nabert (ed.), Tristesee, acédie et médice des âmes. Anthologie de textes rares et inédits (XIIIe-XXe siècle) (pp. 61-83). Paris: Beauchesnes.

Peretó Rivas, R. (2010). Acedia y depresión. Entre pecado capital y desorden psiquiátrico. Actas IV Jornadas Nacionales de Filosofía Medieval. Buenos Aiers: Academia Nacional de Ciencias.

Peretó Rivas, R. (2011a). Acedia y depresión. Aportes para una reconstrucción histórica. Ë̈, 3(1), 1-20.

Peretó Rivas, R. (2011b). Las mutaciones de la acedia. De la Patrística al Medioevo. Studium: filosofía y teología, 14(11), 159-173.

Peretó Rivas, R. (2012). Evagrio Póntico y la exclaustración de la acedia. Carthaginensia: Revista de estudios e investigación, 28(53), 23-35.

Peretó Rivas, R. (2013). 'Moritur in solitudine': la acedia en la vida de Hugo de Miramar. Stylos, 22, 174-186.

Pérez Rincón, H. (2014). La acedia hoy. Editorial. Revista Latinoamericana de Psicopatología Fundamental, 17(2), 169-172. 
Pichery, D.E. (2008). Introduction. In J. Cassien. Conférences I-VII. Paris: Les Éditions du Cerf.

Roudinesco, E., \& Plon, M. (2008). Diccionario de psicoanálisis. Buenos Aires: Paidós.

Rovaletti, M.L., \& Pallares, M. (2014). La acedia como forma de malestar en la sociedad actual. Revista Latinoamericana de Psicopatología Fundamental, 17(1), 51-68.

Strauman, T. (1996). Stability within the self: A longitudinal study of the structural implications of self-discrepancy theory. Journal of Personality and Social Psychology, 71(6), 1142-1153.

Studita, T. (1860). De confessione et pro peccatis satisfactione. Paris: Migne.

Suh, A. (2013). The influence of self-discrepancy between the virtual and real selves in virtual communities.Computers in Human Behavior, 29(1), 246-256.

Symeón le Nouveau Théologien (1957). Chapitres théologiques, gnostiques et ethiques. Ed. J. Darrouzès. Paris: Cerf.

Vázquez, S. (2013). La curación por la palabra. De Platón al primer monacato cristiano. Cauriensia, VIII, 459-472.

\section{Resumens}

(Implicações psicopatológicas da acedia em Evágrio Pontico)

A presente comunicação procura destacar a contribuição de Evágrio Póntico na compreensão etiológica desse padecimento tão próximo à melancolia moderna e à depressão contemporânea, que ele conceituou e sistematizou pela primeira vez como acedia. Alguns elementos da noção freudiana da teoria da melancolia e da autodiscrepância sobre a depressão, principalmente no que se refere ao papel do ideal do ego no dinamismo etiopatogênico, são colocados em relação a seu aporte. Nesse contexto, é evidente a importância histórica da contribuição evagriana que antecipa diversas abordagens posteriores da psicologia e psicopatologia, e integra numa perspectiva espiritual a compreensão etiológica da perturbação psíquica e sua possível terapia.

Palavras-chave: Acedia, depressão, ego ideal, ideal de perfeição

(Psychopathological implications of acedia in Evagrius Ponticus)

The present communication highlights the contribution by Evagrius Ponticus to the etiologic understanding of acedia, a condition that's similar to both modern melancholy and contemporary depression. The concept of acedia is illustrated by means of some elements of the Freudian notions of melancholy and of self-discrepancy about depression, especially regarding the role of the ideal of the ego in the 


\section{ARTIGO}

etiopathogenic dynamism. In this context, we show the historical importance of Evagrius' contribution as it anticipates subsequent psychological and psychopathological approaches and integrates an etiologic understanding of this psychic disturbance and its possible therapy into a spiritual perspective.

Key words: Acedia, depression, ideal ego, ideal of perfection

(Implications psychopathologiques de l'acédie chez Évagre le Pontique)

La communication présente met en relief la contribution d'Évagre le Pontique à la compréhension étiologique de cette souffrance si proche de la mélancolie moderne et de la dépression contemporaine, qu'il a défini et il a systématisée pour la première fois : l'acédie. Quelques éléments de la notion freudienne de mélancolie et de la théorie de l'autodivergence à propos de la dépression, principalement en ce qui concerne le rôle de l'idéal de moi dans le dynamisme etio-pathogène, se mettent en relation avec l'apport d'Évagre. Dans ce contexte, l'importance historique de la contribution de ce penseur est manifeste et elle devance donc à de divers exposés très postérieurs de la psychologie et de la psychopathologie et intègre, dans une perspective spirituelle, la compréhension étiologique de la perturbation psychique et sa thérapie possible.

Mots cles: Acédie, dépression, idéal de moi, idéal de perfection

(Die psychopathologischen Implikationen der Acedia in Euagrios Pontikos)

Der vorliegende Artikel untersucht den Beitrag von Euagrios Pontikos für das ätiologischen Verständnis eines Leidens, dass der modernen Melancholie und der zeitgenössischen Depression nahekommt und von diesem als Erster konzeptualisiert und kategorisiert wurde: die Acedia. Hierbei werden Elemente von Euagrios Pontikos Theorie und Freud's Interpretation der Melancholie und Theorie der Selbstdiskrepanz bezüglich der Depression in Zusammenhang gebracht, um die Rolle des Ichs als Leitbild in der etiopatogenischen Dynamik in Bezug zu seinem Beitrag zu stellen. In diesem Zusammenhang wird die historische Bedeutung der Theorie von Euagrios Pontikos bewiesen, welche sich mit dieser Thematik bereits vor der modernen Psychologie und Psychopathologie auseinandersetzte. Das ätiologische Verständnis von psychologischen Störungen und möglichen Therapien wird hier ebenfalls vom spirituellen Standpunkt beleuchtet.

Schlüsselwörter: Acedia, Depression, Ich-Ideal, Ideal der Vollkommenheit

(Psychopathologischen Folgen der Acedia in Evagrius Ponticus)

\section{(Evágrio Pontico的绝望概念的精神病理学意义)}

本文强调Evagrio Pontico在绝望的定义和系统化对当代忧郁症的病因的 了解的贡献。弗洛伊德对忧郁和自我差异概念的一些内容, 尤其是自我理想在 
病理学的作用, 可与其贡献建立关系。在这种情况下, 很显然Evagrio的贡献具 有历史重要性因为已预期心理和精神病理学的一些解释, 并融合精神的角度看 待此心理障碍及了解治疗病因的可能性。

关键词: 绝望, 忧郁, 自我理想, 完美的理想

Citação/Citation: Vazquez, S. H. (2015, dezembro). Las implicancias psicopatológicas de la acedia en Evagrio Póntico. Revista Latinoamericana de Psicopatologia Fundamental, 18(4), 679-703.

Editores do artigo/Editors: Prof. Dr. Manoel T. Berlinck e Profa. Dra. Sonia Leite

Recebido/Received: 27.10.2014/ 10.27.2014 Aceito/Accepted: 29.1.2015 / 1.29.2015

Copyright: (C) 2009 Associação Universitária de Pesquisa em Psicopatologia Fundamental/ University Association for Research in Fundamental Psychopathology. Este é um artigo de livre acesso, que permite uso irrestrito, distribuição e reprodução em qualquer meio, desde que o autor e a fonte sejam citados / This is an open-access article, which permits unrestricted use, distribution, and reproduction in any medium, provided the original authors and sources are credited. 


\section{ARTIGO}

Financiamento/Funding: O autor declara não ter sido financiado ou apoiado / The author has no support or funding to report.

Conflito de interesses/Conflict of interest: $\mathrm{O}$ autor declara que não há conflito de interesses

/ The author has no conflict of interest to declare.

\section{Santiago Hernán Vazquez}

Profesor y Licenciado en Psicología por la Universidad Nacional de San Luis; Doctorando en Filosofía de la Universidad Nacional de Cuyo - UNCuyo (Luján de Cuyo, Mendoza, AR); Becario doctoral del CONICET con el proyecto "La capacidad terapéutica de la palabra en Evagrio Póntico"; Investigador del Instituto de Filosofía de la UNCuyo y miembro del Centro de Estudios Filosóficos Medievales (CEFIM) de la misma institución; Miembro del proyecto de la Agencia Nacional de Promoción Científica y Tecnológica “"Vida en tensión' (eutonía) en la antropología patrística y medieval"; Profesor adscripto de "Psicología General" de la Licenciatura en Filosofía de la UNCuyo; Presenta publicaciones nacionales e internacionales. Loteo Los Olmos 32 - Vistalba

Luján de Cuyo

Provincia de Mendoza - Argentina

e-mail: santiagohernanvazquez@gmail.com

This is an open-access article, which permits unrestricted use, distribution,

\section{(cc) BY-NC} and reproduction in any medium for non-commercial purposes provided the original authors and sources are credited. 